\title{
LOS DESTINOS DEL ZAPATISMO \\ Y LA CUESTIÓN DE LA AUTONOMÍA
}

\author{
THE FATES OF ZAPATISMO \\ AND THE QUESTION OF AUTONOMY
}

Rafael Miranda Redondo
(Cátedra Interinstitucional
Cornelius Castoriadis)

Entrevistador: “usted qué piensa de la teología de la liberación?”

Miembro del EZLN: "Nosotros nos liberamos sin teología."

\section{RESUMEN}

En el artículo a continuación abordamos la cuestión de los destinos del zapatismo como movimiento social a la luz de la cuestión de la autonomía. Ese cometido lo trabajamos a la luz de hipótesis de Castoriadis en el sentido de que el punto clave, en lo que a la autonomía se refiere, no es la resistencia, la identidad o el comunitarismo, mucho menos el relativismo o el supuesto universalismo y si la relación respecto a la institución que está en el propio origen. En este sentido la prueba de fuego respecto al aporte de los movimientos sociales en el sentido del proyecto de autonomía pasa por la negativa de ocultar el poder instituyente que resignifica el propio origen, sometiendo dicha tendencia a la autoalteración y en ese sentido no respecto de lo que es y si respecto de lo que va a ser. Dos instituciones están en el origen del zapatismo contemporáneo, el marxismo y la teología de la liberación, que en versión tercermundista mesiánica, en boca del fanonísmo y el foquísmo, permean los ambientes del activismo político y de la academia, gracias al ultimo recurso de la identidad como algo esencial. En seguimiento a un prolongado ejercicio de dialogo con esa cultura política adelantamos en el cierre del presente escrito una tendencia al cuestionamiento radical en lo que a la teología de la liberación se refiere por un lado y una asignatura pendiente, un duelo congelado diríamos, respecto al marxismo.

Palabras clave: zapatismo, autonomía, resistencia, identidad, comunitarísmo, ocultamiento, poder instituyente, autoalteración.

\section{ABSTRACT}

In the article below we address the question of the fate of Zapatismo as a social movement in light of the question of autonomy. We work with reference to Castoriadis' hypothesis that the key point in terms of autonomy is not resistance, identity or communitarianism, much less relativism or supposed universalism, but the relationship with respect to the institution that is in its own origin. In this sense, the ultimate test on the contribution of social movements in the sense of the autonomy project goes through the refusal to conceal the institutional power that re-signifies its own origin, subjecting this tendency to self-alteration, not in respect to what it is but to what it is going to be. Two institutions are at the origin of contemporary Zapatism, Marxism and liberation theology. In the third-world messianic version, these institutions encompass fanonism and foquism

\footnotetext{
${ }^{1}$ En la toma de SCLC, 1994, testimonio directo del autor.
} 
and permeate the environments of political activism and academia, thanks to identity being a las resort and something essential. Following a prolonged exercise of dialogue with this political culture, we have advanced in the closure of the present writing, a tendency toward the radical questioning of what the liberation theology refers to on the one hand and a pending subject, a frozen duel we would say, with respect to the Marxism

Keywords: Zapatismo, autonomy, resistance, identity, communitarianism, concealment, institutional power, self-alteration.

\section{Un apunte provisorio de contexto}

En la tradición conocida como "de izquierda", en los últimos años del S. XX y los primeros del S. XXI, los nuevos movimientos sociales se habían diferenciado de la tradicional cultura política obrera. El movimiento de las mujeres, de las minorías, de los jóvenes etc. emergieron en un contexto de perdida de referentes. Las antiguas certezas respecto a las "leyes de la historia", reiteradas por el marxismo, iban a derrumbarse una tras otra. En importante medida este derrumbe, en el campo de la filosofía política, tenía lugar ante la emergencia, en la realidad de las sociedades de capitalismo desarrollado y de capitalismo de Estado, del fenómeno burocrático, en oriente como en occidente y de la condición de dicho sector como "clase" dominante.

Esa perdida de referentes se daba en un contexto en el que la crítica de categorías como aquella del sujeto substancia del racionalismo iba a concretarse por la vía de algunas ideas débiles como el pensamiento posmoderno, el deconstruccionismo, el postestructuralismo y mas recientemente, sobre todo en América Latina, el pensamiento decolonial. Diversos rasgos ineluctables que sirven de elementos articuladores en esas corrientes, paradójicamente, tendrían el mismo carácter de trascendente y transhistórico que el sujeto racional en el pasado reciente.

Sobre el terreno de la acción social y no solo de la academia, toda esa evolución de la "política" recordemos que para varias de esas corrientes "la política" es la fuente de la que se inspira el totalitarismo-, se iba a traducir, en lo que a America Latina se refiere, en un discurso que antaño emparentaba idílicamente al marxismo con el tercermundismo y que para nuestra región integraría a dicho idilio a la teología de la liberación (Cedillo Cedillo, A. 2010, 143). Hoy a ese discurso se la habría sumado el relativismo del todo vale y finalmente de la actual crisis de sentido ${ }^{1}$. El discurso de los derechos humanos, ese substituto contemporáneo de la política, la "gran política" digamos, avocado a causas irreprochables para cualquiera que tenga un mínimo de sentido común ${ }^{2}$, permea el contexto descrito, mas sobre el plano conceptual si se puede decir así.

Como antaño "los obreros" o "la clase obrera" - categoría que, en la medida en que era determinada por la estructura económica, hacía que en ese saco cupieran tanto los obreros de base que reivindicaban el aumento de salarios como los burócratas de los sindicatos que los representaban-, hoy los portavoces de dichos movimientos y el activismo civil que los secunda, están dedicados a reivindicar las causas "de las mujeres", “de los indígenas", "de los jóvenes". Todo ello como si fuera posible asimilar por una condición siempre trascendente a "los indígenas" que, por ejemplo en México, votan por el PRI -la enorme mayoría- y a los indígenas que forman el Congreso Nacional Indígena (CNI) y se reconocen con el Ejercito Zapatista de Liberación Nacional (EZLN); asimilar a "las mujeres" que se resisten a la condena de su deseo a aquellas que crían a sus hijos en estricto apego a la

\footnotetext{
${ }^{1}$ Crisis que aqueja a las sociedades occidentales del capitalismo desarrollado como al resto del planeta, caracterizada por la apatía, el cinismo, la corrupción política, la simulación (Miranda Redondo, R. 2015, 255) en todas las esferas de la vida social y la destrucción del medio ambiente. Esta crisis, parafraseando a Castoriadis, no es la obra de un dictador, de un puñado de grandes capitalistas o de un grupo de formadores de opinión, se trata de una crisis de sentido (Castoriadis, C., 1997, 17)

${ }^{2}$ Ver por ejemplo las recientes revelaciones de espionaje masivo a comunicadores críticos del gobierno priista, de Partido Revolucionario Institucional (PRI), gracias a dispositivos Pegasus que son vendidos por una empresa israelita únicamente a gobiernos, con el fin de que vigilen los movimientos de narcotraficantes y delincuentes peligrosos. Espionaje que viola los mas elementales derechos humanos de esos profesionales (Ver New York Times 19 de junio de 2017)
} 
cultura patriarcal; asimilar a los jóvenes que se organizan para transformar su vida cotidiana a aquellos que cometen crímenes en nombre la superioridad de una "raza" y así sucesivamente.

En las paginas a continuación me propongo desarrollar los aspectos medulares de este contexto a la luz de los destinos del zapatismo y la cuestión de la autonomía.

\section{Origen del desencuentro}

Es importante señalar que lo expuesto esquemáticamente en líneas anteriores tiene lugar en un marco mucho mas amplio sobre el plano filosófico y psicoanalítico, si podemos decirlo de este modo, en el que, desde tiempo inmemoriales, la búsqueda de certezas, en la religión, en la economía, en la ciencia, en "la ética", no es mas que el revés de la negación del tiempo como emergencia perpetua de lo nuevo y finalmente negación de la muerte, de la propia muerte. El sujeto substancia del racionalismo, que había sido sustituido por la ineluctabilidad de la metáfora paterna o aquella de las formaciones discursivas, comparte con estas últimas, como rasgo característico común, la negación y el ocultamiento del poder instituyente que, no obstante, la crisis actual de sentido, sigue transformando el mundo ${ }^{1}$.

La condición por excelencia de la imaginación radical, como fuente de creación de nuevas formas, su precipitación en el hacer pensante reflexivo y deliberante de la política en sentido noble -que nada tiene que ver ni con "los políticos", ni con "los representantes", ni con "los expertos en política"-, es decir la política como institución del conflicto, será reiteradamente ocultada en la contemporaneidad de las ideas débiles mencionadas. La anhelada desaparición del conflicto -por ejemplo, en el comunitarismo identitario ${ }^{2}$-, estará en el origen de una teología -también la teología racional del determinismo-, que aspira a ocultar dicho imaginario en su radicalidad y alteridad, gracias a la multiplicidad, que deriva en la diferencia como ideología. "Todo lo que es real es racional" como máxima y sus efectos, pasando por el tamiz de la culpa de los occidentales contenida en el pensamiento posmoderno y en la mistificación deconstructivista, nos va a llevar derecho a la esencialización de la identidad y al relativismo cultural. A ese universo de significaciones correspondería, como siempre, la socialización de tipos antropológicos, en este caso seres "unidimensionales", victimas pasivas que resisten, grupos de personas que hemos llamado poblaciones cautivas. ${ }^{3}$ Condición per se, como en el caso del racismo -pero en este caso en sentido inverso- cuando profesa que los indígenas, los negros o las mujeres, como consecuencia de su condición étnica o de genero, serían, sin saberlo en la mayoría de los casos, portadores de atributos positivos. ${ }^{4}$ Postura que, inevitablemente terminará en el angelismo y el victimísmo que lo acompaña. Las "mujeres", los "indígenas", los "jóvenes" "son buenos" y si hacen algo malo es porque han sido corrompidos por el sistema, la cultura patriarcal, el indigenismo, la sociedad de consumo etc.

La crítica llevada a cabo del "occidente", no solo por los extremismos islámicos como el califato, sino también y de manera reiterada por la evolución de la filosofía política mencionada, no solo había ignorado -por decir lo menos visto que se trata mas bien de un acto fallido en términos freudianos-, el hecho fundamental que consiste en que, hacer una crítica radical de dicha tradición, a diferencia de lo que ocurre con la enorme mayoría de las tradiciones culturales, confirmaría uno de sus valores mas nobles y fundamentales. También había ignorado, meridiano para nuestro argumento, que al lado de la aberración que erige el dominio racional en significación imaginaria mayor y en nombre de la cual hoy el planeta y la sociedad están convertidos en un gran supermercado, sobrevive, como significación también central de la tradición greco-occidental y de la mejor modernidad, la autonomía como valor. Veamos en qué términos.

\footnotetext{
${ }^{1}$ Casi nunca en el sentido que queremos, pero ese es otro tema.

${ }^{2}$ Ver Miranda Redondo R. 2014 b.

${ }^{3}$ Ver mas adelante.

${ }^{4}$ Ver una postura de contraste en Camus citado por Onfray, 2012, 53, 409
} 


\subsection{Autonomía vs. heteronomía}

Detengámonos un momento para hacer algunas precisiones que son indispensables, si se quiere entender lo que sigue. Cuando hablamos de autonomía de entrada la diferenciamos radical y excluyentemente de la heteronomía: auto-nomía, la norma que viene de mí, por definición excluye la hetero-nomía, la norma que viene del otro. Es así como dicha autonomía como valor positivo, se posiciona, en sus orígenes, no solo ante la verdad revelada sino sobre todo respecto a la posibilidad de que lo dado no esté ahí de una vez y para siempre, es decir que ése sea el producto de nuestro hacer autónomo y si no ¿para qué su ejercicio?

Siempre dentro del paréntesis, obligado por la perorata interminable que en el campo del marxismo se ocupó durante décadas de criticar lo que venía identificado como el "individualismo" pequeño burgués etc. -otro caballito de batalla de lo que evolucionaría en el sentido de convertirse en la ideología de la burocracia en la ex-órbita soviética y en las actuales dictaduras de izquierda en América latina-, se impone una aclaración: no se necesita gran ciencia para constatar que "el individuo" es un fragmento de la colectividad y que por lo tanto está atravesado por las significaciones correspondientes a la institución de cada sociedad de que se trate. La tendencia del mundo capitalista contemporáneo nada tiene que ver con el desarrollo de la dimensión individual -que es para nosotros un elemento positivo en el sentido de la autonomía- y mucho con la privatización de la vida.

Cerrando ese paréntesis aclaratorio reiteremos que la autonomía -una vez expuesta esa dicotomía autonomía vs. heteronomía que es la puerta de entrada para el debate-, como proyecto, surge como un valor al interior del cual el sentido que esta en juego es aquel de la apertura ante la alteridad -alteridad que no es la "diferencia" de la ideología francesa o Dios en la "finitud" de Levinas (Fernández Guerrero, Olaya, 2015, 424)- y si la alteridad que media la relación excluyente entre una sociedad que ve en sus instituciones el resultado de su propio hacer y una sociedad que ve en esas instituciones la obra de una instancia extrasocial.

\section{Relación con la institución que esta en el propio origen}

La historia oficial del nuevo zapatismo como cultura política -el destino mas conocido del zapatismo histórico en la contemporaneidad de México-, nos dice que la autonomía es un objetivo del movimiento (Bellinghausen, H. s/n de pág. última revisión 6 de julio 2017). Queremos, en las líneas a continuación, a partir de una larga experiencia de dialogo con ese movimiento ${ }^{1}$ y con quienes trabajan con él ${ }^{2}$, documentar aquellos avances que el mismo ha logrado concretar en sus varias décadas de existencia respecto, justamente, a la relación con las instituciones que están en su origen. Sin animo de menospreciar los cambios en otros campos, el interés en este caso se centra en el dar cuenta de la manera en que el proyecto de autonomía ha sido puesto en práctica o menos por quienes de ese movimiento se reclaman.

En otro espacio hemos dedicado nuestra atención al zapatismo histórico (Miranda Redondo, R. 2014, 275), en estas líneas, reitero, queremos valorar la manera cómo, quienes se reclaman de esa tradición, se relacionan con las instituciones que están en su propio origen. En la introducción de este escrito hemos adelantado algunos de los rasgos mas genéricos de la tradición contemporánea de "izquierda" oficial y particularmente de la manera como esa tradición se ha precipitado en America Latina y muy especialmente en México. Recojamos de esa reflexión las implicaciones que conlleva lo que Castoriadis va a describir como una indigencia teórica (Castoriadis, 1986, 131) del tercermundismo

\footnotetext{
${ }^{1}$ Desde la instalación de granjas de lombrices para producir composta y comercializar café orgánico por las mujeres de algunas de la comunidades históricas del movimiento, hasta un intercambio constante con habitantes de los caracoles sobre temas como los sistemas de educación, pasando por la participación en múltiples debates con quienes trabajan con los zapatistas en seminarios y foros de diversa índole y con temáticas multiples (Ver la Guía de autoformación de la Cátedra Interinsitucional Cornelius Castoriadis: http://www.agorainternational.org/cicc.pdf, ver por ejemplo las sesiones de los días 26 de noviembre de 2010; 28 de enero de 2011; 7 de mayo de 2010; 2 de marzo de 2011; 4 de marzo de 2011; 1 de abril de 2011; 4 de mayo de 2011)

${ }^{2}$ Mas adelante en la nota sobre procedimiento explicaré porqué, para entender la época victoriana, lo mejor es averiguar las motivaciones de aquellos que se avocan a estudiarla.
} 
que, ante el "aburguesamiento" -y la burocratización diríamos nosotros-, del movimiento obrero en los países industrializados, habrían hecho el salto y emprendido el viaje -ver Sartre- ${ }^{1}$, para "descubrir" en el campesinado de los países pobres al "nuevo" sujeto revolucionario.

En ese contexto y retomando la hipótesis sobre la cuestión clave respecto a la autonomía -reiteramos la relación distinta con la institución propia en donde se ve en esta, no algo impuesto por una instancia extrasocial, las leyes de la historia, la costumbre, los antepasados, dios o las leyes del mercado y sí algo que nosotros nos hemos dado y que por lo tanto podemos modificarlo-, a continuación, me propongo sopesar esa relación para el caso del zapatismo contemporáneo. Para tal efecto, y tomando en cuenta que no necesariamente los lectores de este artículo están al tanto del contexto histórico, daré primero algunas informaciones básicas.

\subsection{La institución del otro}

La época que se inicia con la independencia de México de la Corona Española va a tener un fuerte signo en el sentido de la cultura criolla y la conformación y consolidación de una "identidad nacional". Ya desde entonces y en importante medida gracias a la visión que los misioneros ibéricos trajeron consigo respecto a "los indios", en ese concierto de la formación de un proyecto y una identidad nacional, los pueblos originarios asistieron a la inauguración de la condición impuesta en el sentido de lo que he llamado las poblaciones cautivas ${ }^{2}$.

Antaño "representadas" por los clérigos delegados de la corona y al mismo tiempo portavoces de dichos pueblos -quizás la figura mas emblemática en este sentido sea Fray Bartolomé de las Casas que quería liberar a los indios de los trabajos mas duros, proponiendo que fueran substituidos por los esclavos africanos en esas tareas-, a partir de la independencia y en el conflicto entre liberales y conservadores, dichos pueblos, siempre en su condición de poblaciones cautivas que referimos aquí arriba, serán objeto de ese doble registro en el que, si bien se reivindica su condición en términos constitutivos de la "identidad nacional", nada se hace para asumir sustancialmente las implicaciones de su existencia y su alteridad real, en el contexto de la formación del estado nación y de la cultura mestiza dominante.

El resultado inevitable de esta situación será, en el plano cultural, el indigenismo mexicano, en el que básicamente los indígenas tienen esa condición ambigua y esencialmente basada en una concepción pasiva de dichos pueblos, concepción heredada de la cultura pastoral y de la culpa de los occidentales ${ }^{3}$. En el plano mas de la "democracia representativa" el desenlace tendrá su punto culminante en la cultura clientelar del partido que se mantuvo en el poder durante 80 años, el PRI y sus "sectores populares", cuya estrategia sistemática, durante casi un siglo, ha sido la de fomentar el asistencialismo y el reparto de dadivas a las comunidades indígenas para comprar su voto. Para entender mejor estas ultimas aseveraciones y sus efectos para el tema que nos ocupa, creo que es importante dar algunas pistas de lo que fue el antecedente y el desenlace de la Revolución Mexicana.

\footnotetext{
${ }^{1}$ Ver Onfray, 2012, 437.

${ }^{2}$ Por poblaciones cautivas -en el marco de lo que Castoriadis va a llamar la contradicción entre dirigentes y ejecutantes-, entiendo aquellos sectores marginados de la población cuya condición será utilizada por "representantes" y "portavoces" para fines no manifiestos sobre todo que no necesariamente son aquellos sentidos por dichas poblaciones. Me refiero al tipo de relación que los jesuitas tienen con "los pobres" o mejor con "sus pobres", la relación que las organizaciones civiles establecen con los "grupos vulnerables" y así sucesivamente. El efecto perverso de este tipo de relación transferencial, jamás hecha explicita, no solo es la cancelación de entrada de la autonomía de dichos sectores sino la imagen de los mismos en términos unidimensionales como seres no complejos bajo riesgo de manipulación justamente y por lo tanto "necesitados" de quienes "los representan" y son "sus" portavoces. La relación de mutua dependencia y de asistencialismo que de todo esto deriva es uno de los rasgos fundamentales del actual substituto de la política, la gran política, es decir el "mundo humanitario".

${ }^{3}$ Ver en este sentido, en los ambientes académicos progre o comprometidos la popularidad en años recientes del pensamiento posmoderno y del relativismo cultural derivado, así cómo de posturas postestructuralistas con sus nuevos esencialismos ineluctables y por supuesto la última moda inspirada de la antropología cultural, ese carnaval académico, de la esencialización de lo identitario por el llamado "pensamiento" decolonial.
} 
En efecto el siglo XIX en México representó un importante hito en el conflicto que había enfrentado, durante todo el periodo que sucede a la independencia, a conservadores y liberales. Benito Juárez, indígena zapoteco, después de haber sido "agraciado" por el clero, quien lo apoyó cundo éste se separó de su comunidad de origen y se fue a estudiar a la ciudad, iba a convertirse en el gran precursor de la secularización del país, en la segunda mitad de ese siglo. Incluso anterior a la Ley de separación de la Iglesia y el Estado en Francia (1905), en México las Leyes de Reforma (1855-1861) habían despojado -formalmente al menos-, a la iglesia católica de sus propiedades, en un intento por concretar dicha secularización y en particular con el claro objetivo de disminuir el enorme poderío económico de esa congregación. Es en ese contexto en el que habían llegado las ideas libertarias a México, en particular el fourierismo de Plotino Rhodakanaty de enorme influencia en el primer zapatismo histórico (Miranda Redondo, R. 2014, 300).

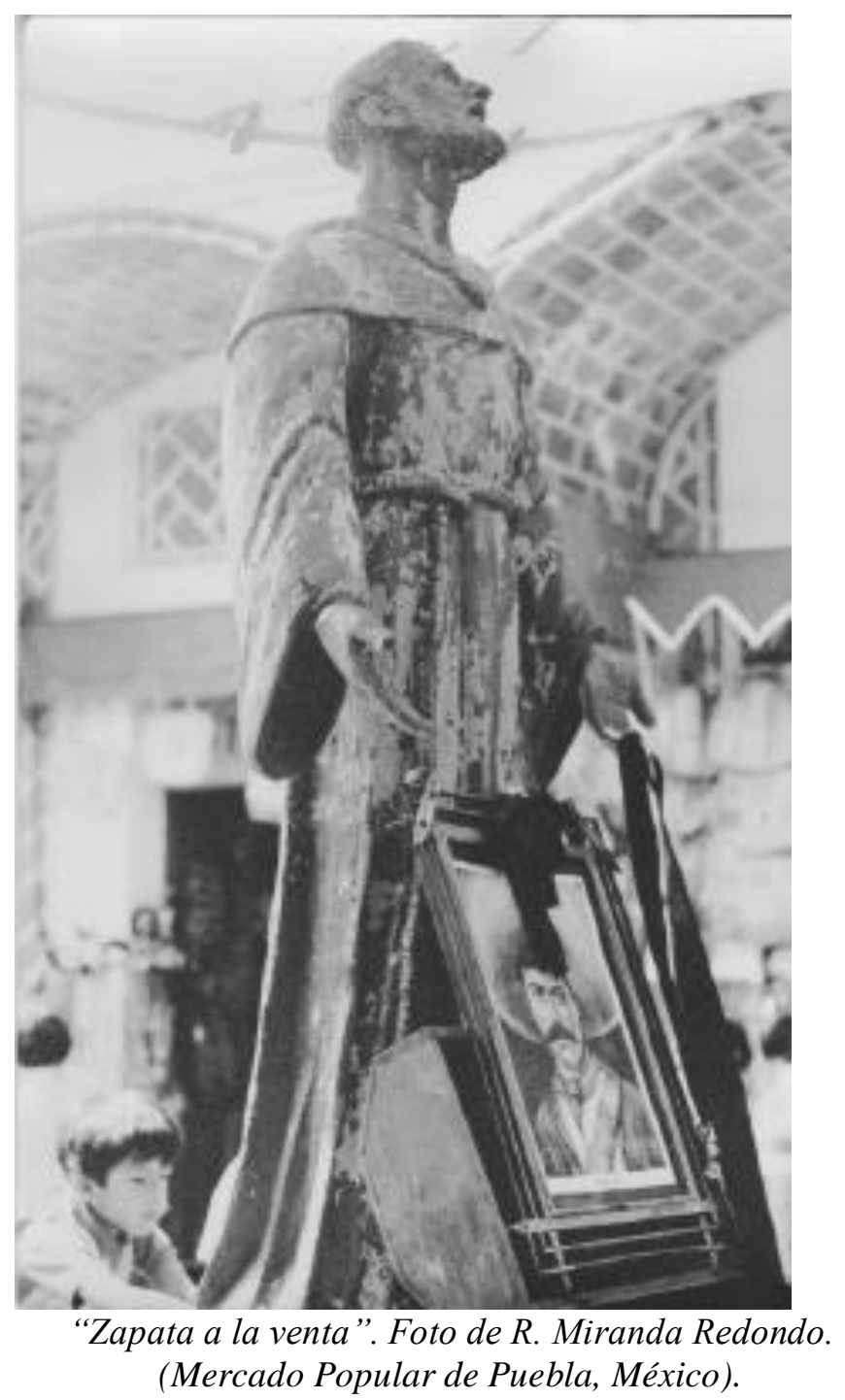

El desenlace de la Revolución Mexicana que había desterrado al dictador Porfirio Díaz y había dejado el poder en manos de los liberales, iba a definirse y consolidarse gracias a un periodo de reacomodo de los jefes revolucionarios "caudillos" y de sus allegados, todo ello hasta formar el Partido Nacional Revolucionario, antecedente del actual Partido Revolucionario Institucional. De nuevo en este contexto, no obstante, la puesta en marcha en importantes regiones del país de la Reforma Agraria y la creación de esa forma de propiedad colectiva denominada el "ejido", la condición de los pueblos indios y la posibilidad de un "pleno desarrollo"1 por parte de esos sería catalogada como asignatura pendiente. Lo anterior no sin la exacerbación de las tendencias mencionadas a integrar, a titulo de

\footnotetext{
${ }^{1}$ Debate que no puedo asumir aquí pero que tampoco puedo dejar de señalar, el "pleno desarrollo", una vez que la idea de progreso perdió credibilidad, ¿sería una reivindicación de dichos pueblos? ¿es el concepto de desarrollo, basado en la racionalidad y en la idea de que mas es bueno y menos es malo, una significación imaginaria social que corresponde a dichos pueblos?. Para mas detalles ver el texto "Desarrollo y racionalidad" de Castoriadis (1986)
} 
estandarte, "lo indio" en los discursos oficiales y en la educación pública, así como -sobre todo en los sectores vinculados a la iglesia-, exacerbar esa concepción angelista, de venerable ancianidad según la cual los indios son seres unidimensionales, por lo tanto "buenos por naturaleza" y solo corrompidos por el sistema ${ }^{1}$. Esa concepción tan común entre las organizaciones bienpensantes de la sociedad civil, en enorme mayoría vinculadas a sectores de iglesia que, por ejemplo, ante la venta del voto en las comunidades indígenas, condenan a los políticos que la promueven, sin hacer ni siquiera mención de que para que el voto sea comprado por esos, alguien tiene que venderlo.

La contemporaneidad de los desarrollos anteriores pasó por un proceso que también debe ser asentado, un proceso de formación de la cultura política "de izquierda" en México. Hemos mencionado ya la temprana llegada de las ideas libertarias al país (Miranda Redondo, R. 2007), también en otro lado nos hemos ocupado de su relativo fracaso (Miranda Redondo, R. 2014, 278). Mas en el curso del siglo XX hubo dos grandes periodos, el primero de formación, un periodo anterior inmediato a la fundación del Partido Comunista Mexicano, con un fuerte ascendente de la tercera internacional y abiertamente estalinista y un segundo periodo que tuvo que ver con un cierto auge del trotskismo en México y con una difusión de las primeras versiones críticas de esa cultura, por ejemplo, en la figura de Victor Serge (Albertani, 2007, última revisión 4 de julio 2017).

En el contexto internacional la inmediata postguerra y el desarrollo del capitalismo en los países industrializados habían no solo dado al traste con la idea de la ineluctabilidad del socialismo, sino que habían visto emerger, tanto en la orbita del capitalismo desarrollado como en la -llamada en ese entonces-, "orbita soviética" el fenómeno burocrático mencionado. Era la época en la que se desarrollaban diversos movimientos de liberación nacional en las todavía existentes colonias, como mencionamos arriba. Notable había sido en ese entonces el impacto para las concepciones de la izquierda oficial en occidente de la Guerra de Argelia. En particular respecto al "socialismo" vinculado a la reivindicación nacional -todavía en boga en algunos movimientos separatistas, mezcla antiestética de banderas, vírgenes, estrellas del football e industriales y funcionarios corruptos- y de manera definitiva respecto al destino, casi infalible, del desenlace de esas luchas en la formación de burocracias que toman el poder anulando cualquier posibilidad de verdadera independencia económica y cualquier forma de autonomía de esos pueblos. Del lado de la "clase obrera" -ver por ejemplo el voto obrero por el Frente nacional en Francia y el voto latino en la reciente elección de Trump en EU-, en los países industrializados, como efecto perverso del estado de bienestar es cierto, pero también debido a procesos más del orden de la búsqueda del confort, la emergencia referida del fenómeno burocrático vino a la par, incluso en las filas del movimiento obrero y la consolidación en la cultura oficial de izquierda, de lo que había ya sido convertido en su ideología: el marxismo.

El tercermundismo referido, ampliamente difundido y promovido por figuras como Sartre -quien en su momento había justificado el régimen de $\operatorname{Stalin}^{2}$, mientras, recordemos, éste creaba campos de

\footnotetext{
1 Otro gran tema que excede los limites de este escrito: el proceso secular por el cual, de nuevo, frente a la instrumentalización del dominio colonial en el dispositivo de las misiones, y su recurso por excelencia la confesión (Foucault, 1999) , la indianidad, como representación de si, será interiorizada por los pueblos originarios en el contexto de una relación, con los misioneros en particular, en la que los procesos de transferencia, en sentido psicoanalítico, van a tener como resultado el establecimiento de una condición apropiada. Representación de sí interiorizada proveniente del discurso de la institución religiosa como vehiculo - por no hablar de la condición de la mujer y de la mujer indígena, también tema fundamental que rebasa por mucho los limites de este escrito-, por momentos titubeante es cierto, del poder colonial. Con lo anterior no pretendo asimilar mecánicamente esa cultura misionera a practicas tales como la inquisición, las cruzadas o el papel de la iglesia católica en la Guerra civil en España, por mencionar solo algunos de los pasajes penosos de ese poder en la historia, sino solamente dejar sentada la sofisticación de los métodos para relacionarse con quienes, en adelante, se convertirán en las mencionadas poblaciones cautivas, por "propia" convicción. Interesante aquí claramente los procesos de sincretismo y situaciones de por sí elocuentes tales como la casi prohibición de criar cabras -“estás loca como una cabra"... profesan los dichos populares de la cultura patriarcal-, en la Nueva España porque esos animales se asociaban al demonio, a "los judíos" y -todo lo contrario- la extensión - ver por ejemplo los indígenas de los Altos de Chiapas-, de la extendida crianza de borregos, esas "dóciles criaturas del señor". De esto último la fuente es Isabel Mora en comunicación personal.

${ }^{2}$ Las fuentes citadas por Castoriadis en su artículo (Castoriadis, 1953) son: "Les Communistes et la paix," originalmente publicado en Les Temps Modernes, 81, 84-85, y 101 (Julio de 1952, Octubre-Noviembre 1952, y AbriI 1954); reimpreso en Situations VI (Paris: Gallimard, 1964), 80-384; y : "Reponse a Claude Lefort," originalmente publicado en Les Temps Modernes, 89 (Abril 1953); reimpreso en Situations VII (Paris: Gallimard, 1965), 7-93,
} 
concentración para los disidentes y opositores (Castoriadis, 1953, 191) y había disimulado los crímenes cometidos por los artífices de la Revolución Cultural China-, iba a solventar la crisis. En este contexto de cultura política mesiánica en America latina íbamos a ver emerger el fanonismo, el foquismo y ulteriormente el maoismo ${ }^{1}$, cuyos destinos históricos son en nuestros días por demás ampliamente conocidos ${ }^{2}$.

Lo dicho en los parágrafos anteriores respecto al contexto del tercermundismo, como cultura política, tendrá una realidad particular en el caso de America latina, realidad en la que queremos insistir. A reserva de poderlo analizar en su dimensión continental, tomando en cuenta el propósito de estas líneas, nos limitamos a sopesarlo para el caso de México. Sin restar importancia al enorme y secular conflicto que caracterizó la formación de una "identidad nacional" en el país y que fue el conflicto mencionado entre la iglesia católica y los sectores liberales, entendidos estos en sentido clásico, creemos que el ulterior encuentro entre la teología de la liberación y el marxismo, precisamente, en un esfuerzo de redefinición muy propio del tercermundismo descrito y opuesto a lo que en el mejor de los casos puede ser denominada una oligarquía neoliberal en el poder, no es nada casual. Lo analizamos mas adelante pero antes hagamos una precisión de procedimiento.

\section{Apunte de procedimiento}

Antes de seguir con este escrito quiero, como prometo en líneas anteriores, hacer un apunte de procedimiento, que me parece necesario para facilitar la comprensión de lo que viene. La alusión en líneas anteriores a la época victoriana y a la manera cómo podemos conocerla, analizando las motivaciones de aquellos que se avocan a estudiarla, tiene como fundamento una formulación de Freud respecto al hecho de que, la materia del psicoanálisis no es el discurso manifiesto y si los procesos transferenciales y contratransferenciales ${ }^{3}$ a los que ese se avoca. Procesos que en una formulación redimensionada por Castoriadis hará referencia directa a la dimensión imaginaria de la sociedad. Parafraseando al autor digamos que no podemos cambiar lo que ocurrió, pero si podemos cambiar la manera de interpretarlo. Es así como el zapatismo de hoy sería el resultado de una serie de procesos de sentido, conscientes e inconscientes, que tienen lugar en la escena de la relación, latente o manifiesta, de los zapatistas con quienes no lo son y con las instituciones que están en su origen. Un proceso haciéndose que esta alejado de las declaraciones y que da la dimensión real de esa cultura contestataria. Lo anterior me lleva a considerar como fundamental el andamiaje transferencial que se establece entre los zapatistas y quienes trabajan con ellos ${ }^{4}$.

Ahora bien dicho lo anterior adelantemos una cuestión fundamental, la posibilidad de la autonomía va a definirse precisamente en ese entramado de procesos de sentido, pero sobre todo en su explicitación, lo que Castoriadis va a definir como la reflexividad, es decir el pensar pero sobre todo el pensar-se. Todas las sociedades y los colectivos se autoconstituyen, no obstante, lo anterior, solo algunos lo hacen de manera explicita y son precisamente estos los que, en su hacer y en su hacer-se, van a ver en la autonomía un valor positivo. Estas sociedades y colectivos, al explicitar su proceso de autoinstitución, teniendo delante el magma de significaciones imaginarias sociales que están en su propio origen, van a reconocer que ellos están, insisto, con su hacer, en el origen de sus instituciones y que por lo tanto no hay instancia extra-social que los rija. Lo que en términos psicoanalíticos puede asociarse a la explicitación de la transferencia de la que emerge el sujeto autónomo. La autonomía en este sentido es el gobierno por el cual, quien la ejerce, decide gobernarse. Nos dice Castoriadis,

\footnotetext{
${ }^{1}$ En 1979, año en el que se establecieron las Fuerzas de Liberación Nacional en Chiapas -de donde posteriormente emergió el Ejercito Zapatista de Liberación Nacional-, en una travesía por la Cuenca del Río Jataté, de San Cristóbal a San Quintín, quien suscribe tuvo oportunidad de encontrar y dialogar, en las comunidades de la zona, con numerosos maestros rurales de corta edad, abrumados, tratando de leer y entender el Libro Rojo de Mao.

${ }^{2}$ Ver por ejemplo los movimientos armados en America Central durante la década de los años 80s.

${ }^{3}$ Ver mas adelante.

${ }^{4}$ Interesantísimo el testimonio en este sentido de la Brigada los Nadie bajo el título ONU, PNUD, ONGs y Zapatistas. Historias que deben ser contadas en el sureste Mexicano (Parte 1 y 2). Documento en formato pdf. no publicado.
} 
La aparición de la reflexión no puede, por lo tanto, tener lugar más que con un cataclismo y una reconducción fundamental de todo el campo social-histórico, en la medida en que ella implica la emergencia, simultánea y recíproca, condicionante de una sociedad en la que no existe más la verdad sagrada (revelada) y [la emergencia, RM] de individuos para los cuales se ha hecho psíquicamente posible, tanto cuestionar el fundamento del orden social (y eventualmente reaprobarlo) como [cuestionarse, RM] aquel [orden, $\mathrm{RM}$ ] respecto a su propio pensamiento, es decir, respecto a su propia identidad (FF Castoriadis,, 1997g, 277).

\section{En el origen de esa cultura política}

Después de varias décadas de convivir con esta cultura política y siempre profundamente respetuoso del deseo de los zapatistas contemporáneos en el sentido del cometido según el cual, lo que se sepa de ellos, debe ser el resultado de lo que ellos narran en primera persona, ha sido para mi profundamente aleccionador dialogar con aquellos que, trabajando con los zapatistas, hablan de su trabajo en primera persona. De entrada, como es el caso de la enorme mayoría de los movimientos sociales contestatarios en el continente en las ultimas décadas, es importante señalar que de manera casi sin excepción los interlocutores que he tenido todos estos años provienen o del marxismo o de la teología de la liberación y en importante medida de una mezcla criolla de ambos. ${ }^{1}$

La argumentación de Castoriadis $(1975,60)$ en este sentido nos conduce a pensar que la coincidencia de ambas posturas, que por cierto identifican en instancias extrasociales el origen de las instituciones en un caso la "voluntad divina" y en el otro las "leyes de la historia"-, no es nada casual. En ambos casos, al establecer dichos orígenes en instancias extrasociales, se anula de entrada la posibilidad de que la sociedad que tenemos delante sea la obra del ejercicio de la autonomía por parte de aquellos que la constituimos. En otro lado (Miranda, 2008) he dedicado mas explicaciones a este asunto por lo que aquí me limito solo a dejarlo anotado. Vayamos pues a desarrollar algunas líneas que pudieran, en el sentido del objetivo principal de este escrito, replantear la cuestión de la autonomía como la hemos discutido, para posteriormente abordar aquellos aspectos en los que el nuevo zapatismo ha contribuido o no a ese proyecto.

Parto de la hipótesis de que en el origen de la cultura política de quienes trabajan con los zapatistas están esas dos instituciones mencionadas, por un lado, una versión criolla del marxismo y por el otro la variante "teología de la liberación", ${ }^{2}$ como establecimiento de la iglesia católica. Una tercera institución que me parece fundamental en esta relación, pero que no abordo en este espacio, a pesar de que hago mención en líneas anteriores, es sin duda el aporte a la identidad indígena por parte de la empresa colonial y muy particularmente lo que en este sentido proviene de la interiorización de la "representación de sí" -esa institución del otro interiorizada-, por la vía de la confesión, entre otros, como hemos dicho, que los misioneros católicos promovieron en su trabajo con los indígenas, como condición para que estos pasaran a ser "parte de este mundo". Castoriadis se refiere a esto ultimo y mas en general al papel de las instituciones para intentar ocultar el caos que es el no sentido, gracias a la clausura de un orden, en su diálogo con Octavio Paz, Jorge Semprún y Carlos Barral (1991, 3):

De este abismo, de este caos, la humanidad ha tenido siempre una percepción a la vez aguda y confusa. La humanidad ha experimentado siempre su carácter intolerable e insuperable. Ella ha dado respuesta a través de las instituciones sociales y particularmente por aquella que, casi en todos los casos, casi siempre, ha sido el componente nuclear de la cuestión, la religión. La humanidad, por este medio, lo ha reconocido llamándolo trascendencia, hablando de la finitud del hombre. Lo recubre y lo oculta enmascarándolo bajo formas y figuras precisas, figuras de dioses, lugares, palabras y libros sagrados destinados a captarlo, a domesticarlo. Mal que bien, a hacerlo equiparable a aquello que, para nosotros,

\footnotetext{
${ }^{1}$ Aquí es importante señalar la presencia, aunque escasa, de sectores libertarios, algunos de los cuales por economía o por concesión con los relativismos culturales se han mas o menos plegado a las dos instituciones de origen de esa cultura política.

${ }^{2}$ Sobre el encuentro no casual de marxismo y teología de la liberación Cedillo Cedillo (2010, 149) profundiza sobre la "coincidencia imaginaria" entre el milenarismo indígena, ampliamente adoptado como consigna de la "teologíaa indigena" y el mesianismo guerrillero.
} 
puede cobrar sentido. Es por eso que la religión es, para usar un término psicoanalítico, una inmensa formación de compromiso. La materialización —el acta notarial - de ese compromiso es lo sagrado. Lo sagrado se presenta como, y pretende ser, la manifestación y la realización precisa y circunscrita del abismo en el mundo de las apariencias: Dios dentro de la iglesia o Dios en una hogaza de pan, la "presencia real". De la duplicidad invasora de ese compromiso, quizás no hay ejemplo más definitivo que la misa cristiana de los muertos: en ella, al mismo tiempo, se reconoce la nulidad de la existencia humana - pulvis, cinic y nihil - y se afirma la certidumbre de una dicha eterna en el seno de un Padre infinitamente bueno.

\subsection{Preguntarse sobre el orden ${ }^{1}$ para ser autónomo}

La reciente iniciativa de lanzamiento de una candidata "mujer" e "indígena" del CNI que concluyó con la postulación de María de Jesús Patricio Martínez, Marichuy, después de un momento de desconcierto, fue interpretado como una acción mediática, para relanzar la cuestión de la lucha zapatista en el presente. Todo ello esta siendo vivido, en la discreción, como una gran parodia por quienes trabajan con los zapatistas, que además saben que ese movimiento no solo se ha opuesto al voto en el pasado, argumentando que a ellos "no les interesa el poder", sino que incluso prácticamente ningún zapatista cuenta con la credencial del Instituto Nacional Electoral necesaria para ejercer el voto. En todo caso hay que reconocer que poco a poco esa postulación se ha traducido en procesos de consulta y reflexión sobre los objetivos a lograr.

Ese plano manifiesto, cuya importancia claramente no es menor, a menudo sirve de distractor (Castoriadis, 1977, 50) de otro proceso, más en el plano de lo latente y -desde la perspectiva de este escrito-, mucho mas en el sentido de la modificación radical de la relación, no con la institución impuesta por el otro -llámese democracia representativa, capitalismo de Estado o régimen gobernado por una oligarquía liberal-, sino de la relación con la institución que está en el propio origen. En la perspectiva del autor podríamos decir que si bien ese golpe mediático de la candidata "mujer indígena" tiene delante aquello que es, es decir la sociedad de seudo-capitalismo dependiente favorecido por la corrupción de su clase política y por la violencia que se ha generado como consecuencia de la guerra al narcotráfico (Miranda, R., 2015, 257), el proceso que describimos a continuación tiene delante aquello que va a ser, es decir la sociedad que tendrá lugar cundo la que tenemos delante se transforme radicalmente gracias al hacer de los sujetos autónomos.

Siempre de manera muy genérica la tradición católica en México pasó por el proceso descrito arriba de secularización, misma que tuvo lugar en el plano del estado de ley a la hora de la formulación, gracias al empuje de Benito Juárez y sus allegados, de las Leyes de Reforma en la segunda mitad del S XIX. Sobre el plano del estado de derecho dichas leyes tuvieron un impacto limitado. Es cierto que la cultura laica impregnó el proyecto de educación pública y que las instituciones del Estado profesaron durante toda la época del México moderno esa filosofía. Otra historia es lo que sucedía en el seno de las familias, las comunidades apartadas del agro mexicano e incluso en muchos sectores populares urbanos. El poder de la iglesia católica perduró y perdura profundamente arraigado en la cultura del pueblo en la región y con esto hablo de manera particular de los valores de la familia, la concepción de la mujer, la condena del deseo, la moral y la ética y así sucesivamente. También es cierto que mientras que la iglesia católica, a través de sus corrientes mas conservadoras ${ }^{2}$, perdían terreno en los sectores mas desfavorecidos ante la penetración de las religiones protestantes, evangélicas, pentecostesas, testigos de Jehová, ortodoxos, musulmanes etc. (Cedillo Cedillo, A. 2008, 284) a partir del Concilio Vaticano Segundo (1962-1965) y de la segunda Conferencia General del Episcopado Latinoamericano (1968) veremos emerger lo que en medios locales se conoce como la mencionada teología de la liberación (Gutiérrez, G. 2008, s/n de pág. última revisión 4 de julio 2017), la iglesia de los pobres, la

\footnotetext{
${ }^{1}$ La alusión se inspira del titulo de la biografía filosófica de Albert Camus por Michel Onfray: L’ordre libertaire (El orden libertario), 2012.

${ }^{2}$ Ver aquí el prolífico trabajo documental y analítico del fenómeno religioso en México por parte de Fernando González $(2003,2005,2007)$
} 
pastoral social entre otros y a ultimas fechas, en medios académicos sobre todo, la propuesta del pensamiento decolonial promovida por neo-teólogos de inspiración heideggeriana

El mencionado Concilio y sus efectos respecto a la emergencia de una versión de la doctrina católica que volvía la mirada hacia los sectores pobres de la sociedad, es claro que responde a una tendencia, orgánica a toda institución que se interroga, respecto a los principios que la sustentan. Sabemos que dicha interrogación, en el caso de las religiones monoteistas que la han acogido, tiene un limite, no nos detendremos a analizar estos procesos porque no es el propósito de este escrito, solo queremos para ilustrar lo dicho mencionar eventos tan contundentes como la Reforma Protestante, el ecumenismo y en el caso que nos ocupa la citada teología de la liberación y su derivado en la "teología indígena". En México ese período sucesivo a dicho Concilio estuvo marcado en la época por figuras como Méndez Arceo e Ivan Ilich en Cuernavaca y también, aunque con un significado diferente, la figura inspiradora de Lemercier (González, F. 2011, 98).

El contexto y la cultura que se deriva de lo descrito en líneas anteriores, de manera por demás sucinta, está en el origen de un numero importante de "organizaciones de la sociedad civil" que han ejercido un activismo importante en la segunda mitad del siglo XX en el país. También es notable la presencia de esa cultura en muchos de los movimientos armados locales, particularmente en los años 60-70s. Igualmente instituciones educativas con un claro perfil afín a las significaciones imaginarias sociales que están ahí de por medio, han formulado verdaderos programas de formación curricular, a menudo, irónicamente, dirigidos a formar a los hijos de buenas familias católicas bienpensantes a la voz de la "educación popular" y la "educación como práctica de la libertad". En éste último sentido el encuentro entre esta corriente y el denominado pensamiento decolonial, formulado y promovido por académicos latinoamericanos en importante medida provenientes de los sectores de iglesia e instalados como docentes en universidades en Estados Unidos, es por demás elocuente y paradoxal, porqué no decirlo.

Es entonces este el contexto en el que, en los últimos 20 años, aunque ya antes se daba el fenómeno, pero con características menos masivas, a raíz del levantamiento zapatista tuvo lugar, en los Altos de Chiapas y particularmente en San Cristóbal de las Casas, una masiva procesión de jóvenes provenientes de esos medios descritos tanto de México como del extranjero. Durante las dos últimas décadas hemos visto ese peregrinaje inundar las calles de la ciudad y colmar todos los aspectos considerados importantes por el "trabajo en comunidad" en las poblaciones aledañas. Por dar solo un ejemplo, en años recientes y gracias a la empatía de una universidad pública de la Ciudad de México (Universidad Autónoma Metropolitana-Xochimilco), tuvimos ocasión de corroborar la presencia, en San Cristóbal de las Casas, de 600 ONGs operando desde este centro urbano que cuenta con 200000 habitantes.

El panorama descrito es del conocimiento público y profundizar en ello no es el propósito de este escrito. Lo que sí es fundamental para el argumento presente tiene que ver con un fenómeno mucho menos aparente y que consiste en el distanciamiento, por parte de muchos de esos jóvenes, respecto a la estructura eclesial e incluso muchas veces respecto a la propia creencia religiosa. En efecto 20 años de observación nos han permitido dar cuenta de la masiva proporción de esa tendencia, no obstante, por razones que son comprensibles, ha habido un total subregistro del fenómeno. Lo descrito por Fernando González ( 2011, 95 y signs.) respecto al monasterio de Santa María de la Resurrección tiene un carácter bastante excepcional, no por la frecuencia de ese tipo de eventos en la historia de la institución eclesiástica, presencia que es de proporción ${ }^{1}$, véase por ejemplo los países de Europa occidental, sino por el hecho de que dicho evento se dio a conocer, se analizó y se difundió cosa que por regla no ocurre.

La historia de deserción, de distanciamiento de la orden y del orden dictado por la institución de la teología de la liberación, de los jóvenes mencionados, para el caso de la cultura política que ha girado en torno al movimiento zapatista en los últimos 20 años, es de importancia mayúscula. Su análisis pormenorizado exige una atención particular que deberá ser atendida en el futuro inmediato. Desde

${ }^{1}$ Ver Ilich, Iván (1967) “El clero, una “especie” en extinción” citado por Fernando González (2011: 98). 
jóvenes misioneros hasta jóvenes laicos que llegaron a la región en el contexto de programas y/o proyectos orientados a incidir en la dinámica local, los casos se repiten profusamente a pesar de que, repetimos, su conocimiento público es muy limitado ${ }^{1}$. Algunos de esos distanciamientos en la localidad son del orden de lo emblemático como es el caso del párroco de la Iglesia de Guadalupe, Heberto Morales ${ }^{2}$, quien, no obstante, se separó de la iglesia en años anteriores al movimiento zapatista, sentó un precedente simbólico respecto a lo que aquí ilustramos. A ese caso se suman numerosos académicos, algunos mas cercanos a la teología de la liberación y al pensamiento decolonial y otros menos, asesores de los zapatistas. Algunos siguen siendo creyentes, renuentes ante el establecimiento, pero fieles a la institución, otros han roto completamente con la religión. El caso de los mas jóvenes, menos notorios por razones lógicas, son mucho mas numerosos, activos en la zona, algunos de ellos después de haber pasado tiempo en prisión por sus vínculos con organizaciones armadas, sus biografías, historias de bajo perfil, son un testimonio de la historia social, no solo de la región sino claramente de la evolución de una cultura política que se resignifica en la serenidad anónima de la vida individual.

Es este un fenómeno emergente que para la cultura política del zapatismo me parece mas notorio y significativo. Retomando el planteamiento general de este escrito son esas historias de vida y su desenlace -a menudo en iniciativas como la Ley de las mujeres promulgada por los zapatistas que, ahí en donde no se limitan al estado de ley y sí terminan integrándose al estado de derecho-, lo que da cuenta de los mayores meritos de dicho movimiento respecto a las instituciones que están en el propio origen del actual zapatismo y por lo tato respecto a la posibilidad de la autonomía ${ }^{3}$.

\subsection{Identidad como último recurso}

La modificación de la relación con el marxismo, a años luz geográficos, pero también imaginarios del totalitarismo soviético, en las filas de los movimientos sociales en America latina, incluido el nuevo zapatismo, sigue siendo una asignatura pendiente respecto a las nociones núcleo. Para éste último el lenguaje original, cargado de dogmatismo y xenofobia ${ }^{4}$, fue sofisticándose. Algunas herencias del foquísmo original, en el que las acciones puntuales de un grupo interactivo "llevaría" a una situación insostenible que -como si se tratara de la reacción de un organismo a un estimulo- ${ }^{5}$, el pueblo adheriría a la acción de los insurgentes, revolucionarios profesionales, fueron paulatinamente abandonadas.

Pero quizás la mayor ausencia tuvo que ver con la total indiferencia respecto -justamente-, a la manera como, ya en los años 50s del siglo pasado -en medios de la izquierda radical europea pero también en medios libertarios en America latina y teniendo delante la evolución de la Ex-Unión Soviética y del capitalismo desarrollado-, se hablaba de los limites de la contradicción entre capital y trabajo y del mayúsculo alcance explicativo, para el mundo contemporáneo, de la división entre quien dirige y quien ejecuta. Es cierto que haber reconocido la centralidad de dicha división habría llevado al traste no solo a los marxismos -puestos en práctica en America latina, a menudo bajo la formula de que las nacionalizaciones "son" el socialismo-, sino sobre todo que ese reconocimiento suponía constatar que la burocracia, a pesar de no ser una clase en sentido tradicional, se apropiaba del poder, gracias a procesos que nada tienen que ver con el materialismo dialéctico y si con la interiorización por las sociedades de la significación del dominio racional y de la subsecuente jerarquía. Es decir, tienen que

\footnotetext{
${ }^{1}$ Otro aspecto muy interesante en este sentido tiene que ver con la presencia y a menudo el establecimiento de residencia de jóvenes de origen diverso pero muy particularmente españoles, del País Vasco y de Cataluña en especial, que de haber sido educados en instituciones ligadas a la iglesia católica en el postfranquismo han continuado su proceso en las filas de los grupos locales de apoyo al zapatismo. El caso de muchas mujeres activistas, desde el enfoque de genero y el feminismo, con este perfil, es digno de un abordaje mas pormenorizado mismo que no puedo asumir en este espacio.

${ }^{2}$ Historiador y novelista (Morales, Heberto, 2010), profesor, Rector de la UNACH.

${ }^{3}$ Cedillo Cedillo, A. $(2010,154)$ en esta parte sostiene una versión de la autonomía que es contraria a la que en este escrito formulamos, en acuerdo con Castoriadis, cuando dice, por ejemplo: "Si se quiere ver así, había una voluntad de autonomía, estimulada por la negativa de los kaxlanes (blancos o ladinos) a aceptar las especificidades culturales de los indios expresadas en la religión."

${ }^{4}$ Recordemos en la toma de San Cristóbal de las Casas el primer discurso radiofónico del 1 de enero de 1994 en el que todos los males de México eran culpa de "los extranjeros".

${ }^{5}$ Pensamos inevitablemente en los perros de Pavlov (ver Miranda Redondo, R. 2016).
} 
ver con procesos propios de la "superestructura". Las posturas anticapitalistas, siempre prisioneras de la contradicción entre capital y trabajo mencionada, que por momentos aparecen en el escenario del continente, para el caso del nuevo zapatismo y en particular para los pueblos indios que adhieren al movimiento por ejemplo, pasan por alto no solo que la resistencia no es un proyecto político, sino particularmente que esa postura anticapitalista la han reivindicado personajes y culturas políticas tan siniestros como Stalin, Pol Pot y mas recientemente el Califato.

Ante la debacle de las certezas que tuvo lugar en aquel entonces, respecto a las tesis principales de Marx, la que describo aquí arriba pareciera ser solamente una más para añadir a la lista. El problema en este caso, en el sentido precisamente de descubrir que la burocracia no podía querer la revolución porque esa supondría el fin de sus privilegios, tenía que ser enmendado de otra forma. Hablamos arriba de la cuestión del tercermunismo ante la evolución del movimiento obrero y la realidad que emergía de la sociedad soviética ${ }^{1}$, dicho tercermundismo, con toda su carga mesiánica, había sobrevivido como cultura "contestataria" en el continente, él mismo se iba a traducir en el elogio del "desarrollo" y la planificación, cuando no francamente de la ingeniería social. Pero hacia falta un argumento que vinculara la región desde una perspectiva mas vernácula. Es aquí en donde, como había sucedido también en otras latitudes -en ocasiones con desenlaces dramáticos, como el delirio antisemita-, el paliativo de la identidad ${ }^{2}$ venía a ofrecer el recurso indispensable.

Ante la emergencia del fenómeno burocrático, el escamoteo de la necesaria e inaplazable critica del marxismo y del propio Marx en el continente, iba a orquestarse en nombre de la "identidad latinoamericana" 3 alejada de pensadores pertenecientes al occidente decadente. Curiosamente -no tanto en la academia sino sobre todo en el mundo militante-, este argumento disimulaba el hecho de ser él mismo esgrimido desde las posiciones de Marx y Cristo -esos nativos de la periferia de la Ciudad de México-Gran Tenochtitlan-. No pasó mucho tiempo para que a esta formula poco clara se uniera la cuestión de los pueblos indios y de esa versión continental que es el salvavidas del pensamiento decolonial y la centralidad que este concede a la identidad como algo esencial.

\section{Cerrando para abrir}

Habíamos tocado el tema de la identidad como ultimo recurso, que conlleva procesos de sentido del orden de la permanencia del estado de transferencia institucional ${ }^{4}$, en párrafos anteriores, por esta razón y con animo de ir cerrando este escrito solo adelanto algunas conclusiones provisorias. He hecho un recorrido somero de la crisis de referentes que significó para la filosofía y la cultura políticas "de izquierda" el derrumbe de las certezas antaño incuestionables que acompañaron al marxismo, durante las décadas anteriores a la segunda mitad del S XX y en particular anteriores a caída del muro de Berlín. Lo anterior me ha servido para dar el contexto de la cuestión política, en sentido noble, respecto a la manera como dicho derrumbe ha sido -mas que asumido-, disimulado en medios latinoamericanos y el importante papel que en ello ha jugado la teología de la liberación y el propio marxismo en versión criolla, como ideología de la burocracia en el continente. Son esos grandes rasgos los que me han permitido ubicar el marco en el que había tenido lugar ese movimiento que se reclama del zapatismo histórico y que se aglutina en torno a instancias como el EZLN y el CNI entre otros.

\footnotetext{
${ }^{1}$ En el debate entre la izquierda oficial de la época y quienes empezaron a denunciar la sociedad sovietica como una sociedad totalitaria es conocida la aseveración de Sartre en el sentido de que "Socialisme ou Barbarie tenia razón en la época, pero estaba equivocado al decirlo" a lo que los militantes de esa organización habrían replicado: entonces Sartre tiene razón al estar equivocado.

${ }^{2}$ Cedillo Cedillo, A. Nos dice (2010, 169) que en 1980 un grupo de cuadros de la DSC (Diócesis de San Cristóbal), agentes de pastoral tuhuneltik, y catequistas se habrían posicionado en contra de los kashlanes (mestizos) maoistas con la intención de reforzar "la identidad indígena".

${ }^{3}$ Ver Gutiérrez, G. 2008, por ejemplo.

${ }^{4}$ El concepto original proviene de Freud y tiene que ver con el proceso por el cual el analizado transfiere en la figura del analizante a la figura parental, el análisis institucional ha hecho de esta noción un elemento que puede ser aplicado en procesos colectivos por ejemplo respecto a la relación de repetición que prevalece entre una comunidad y sus lideres, en el caciquismo por ejemplo.
} 
Al introducir la cuestión del fenómeno burocrático y de la división entre dirigentes y ejecutantes he querido resaltar la asignatura pendiente de la cultura política de izquierda en el continente y aquí incluyo al propio zapatismo, respecto a la critica radical de esa doctrina que se encuentra en el origen de su propia institución. Al recuperar las manifestaciones que en el campo menos visible han emergido a través de las deserciones de las filas de las estructuras eclesiales y de influencia de la teología de la liberación -esa otra institución constitutiva del movimiento-, he querido llevar al debate la cuestión de la autonomía como proyecto y señalar el potencial que en este sentido representa dicho distanciamiento, como manifestación de una relación distinta con la institución propia, en la que se da la espalda a cualquier instancia extra-social como origen de la propia norma, accediendo así al reconocimiento del hacer propio instituyente como la fuente de la misma.

Este proceso de resignificación, la cuestión de la interrogación respecto al orden de origen, que hemos podido observar, contrasta con el duelo congelado que caracteriza esa misma relación respecto a la otra institución constitutiva, el marxismo. La resignificación en curso de la relación con la teología de la liberación y la ausencia de ella respecto al marxismo, como apuntamos desde una lectura que reconoce relevancia política al psicoanálisis, va a dar cuenta de la emergencia de un sujeto autónomo que se debate con aquello que le da identidad en el origen y que, en el primer caso, al hacer explicita la transferencia institucional respecto a la religión como institución de fundante, se va a reconocer en su propio hacer como fuente de creación de sociedad.

\section{RMR 05/2017 SCLC-CDMX}

\section{Referencias Bibliográficas}

AZAM, Ahmed y PERLROTH, Nicole. (2017). "Somos los nuevos enemigos del Estado: el espionaje a activistas y periodistas", En The New York Time, s/n de pág. última revisión 6-07-2017.

ALBERTANI, Claudio. (2007). Socialismo y libertad. El exilio antiautoritario de Europa en México y la lucha contra el estalinismo (1940-1950). Fundación Andreu Nin , 2007, s/n de pág. última revisión 6-07-2017.

BELLINGHAUSEN, Hermann. (28 de septiembre de 2004). "La autonomía, ejercicio pleno mediante las juntas de buen gobierno en Chiapas”. La Jornada Semanal, s/n de pág. última revisión 6-07-2017.

CEDILLO Cedillo, Adela. (2010). El suspiro del silencio de la reconstrucción de las Fuerzas de Liberación Nacional a la fundación del Ejercito Zapatista de Liberación Nacional (1974-1983). México: Tesis para obtener el grado de Maestra en Estudios Latinoamericanos, Universidad Nacional Autónoma de México.

---, (2008). El fuego y el silencio. Historias de las Fuerzas de Liberación Nacional Mexicanas (1969974). México: Tesis para obtener el grado de Licenciatura en Historia. Universidad Nacional Autónoma de México.

CASTORIADIS, Cornelius (1975). L'institution imaginaire de la société. Paris: Seuil.

---, (1982). “La crise des sociétés occidentales”. En La montée de l'insignifiance. Paris: Seuil. 11-27

---, (20-26 junio 1977). “Les divertisseurs”. En Le Nouvel Observateur, 658 S/D 50-51.

---, (1986). "Réflexions sur le 'développement' et la 'rationalité'”. En Domaines de l'homme. Les carrefours du labyrinthe II.. Paris: Seuil. 159-214

---, (1997). "Freud la sociedad, la historia". En El avance de la insignificancia. Encrucijadas del laberinto IV. Buenos Aires: EudeBA. 
CASTORIADIS, Cornelius. (1974). "Sartre le stalinisme et les ouvriers". En L'Expérience du mouvement ouvrier. Tome 1: Comment lutter. Paris: Union Générale d'Éditions.

---, (1991). "Rencontre-débat entre Cornelius Castoriadis, Octavio Paz, Jorge Semprun et Carlos Barral". En Détours d'écriture. Paris: Noël Blandin Ed. 81-98

---, (1986). “Tiers monde tiermondisme et democratie". En Domaines de l'homme. Les carrefours du labyrinthe II. Paris: Suil. 128-138

FERNANDEZ Guerrero, Olaya. (2015). "Levinas y la alteridad: cinco planos". En BROCAR, Cuadernos de investigación histórica, No. 39, 423-443.

FOUCAULT, Michel. (1999). “La confesión”. En Les anormaux: cours au Collège de France (19741975) (s/n de pág. última revisión 6-07-2017). Paris: Seuil.

GONZÁLEZ, Fernando. (2011). Crisis de fe. Psicoanálisis en el monasterio de Santa María de la Resurrección 1961-1968. México: Tusquets.

---, (2005). "Un conflicto universitario entre católicos: La fundación del Instituto de Estudios Superiores de Occidente (ITESO)”. Em Vetas. Revista de El Colegio de San Luis, 20-21, 9-36.

---, (2007). Algunos grupos radicales de izquierda y de derecha con influencia católica en México (1965-1975). México: Universidad Iberoamericana.

---, (14-09-2008). “Cuarenta años de la Teología de la Liberación” (Entrevista a) Por Ángel Darío Carrero. En La Jornada Semanal, s/n de pág. última revisión 6-07-2017.

LEVINAS, Emmanuel. (1999). Totalidad e Infinito. Salamanca: Sígueme.

MIRANDA Redondo, Rafael. (2016). "El truco del foquismo y la privatización de la educación pública en México". 4-07-2017, En Trasversales, revista de opinión social, política y cultural Sitio web: • http://www.trasversales.net/t38miranda.pdf

---, (2015). "Ayotzinapa y la sociedad que queremos". En La Noche de Iguala y el Despertar de México. Textos, imágenes y poemas contra la barbarie. México: Juan Pablos Editor S. A. 253-276

---, (2014 a). “¡Tierra...y libertad! Socialismo libertario: Amor secreto y desengaño del zapatismo histórico" En Autonomía y autogestión. Andalucía (Estado Español): Colectivo de ilusionistas sociales. 271-306

---, (2014 b). "Estado del proyecto de autonomía y esencialización de lo identitario. Notas sobre America Latina desde Castoriadis". En Revista electrónica Pueblos y Fronteras, PROIMMSE-IIAUNAM Sitio web: http://www.redalyc.org/articulo.oa?id=90628980002

---, (2008). "Castoriadis y el regreso de lo religioso. Auto-alteración de la sociedad y meta-norma". Em LiminaR. Estudios sociales y Humanísticos. Año 6, , vol. VI, núm. 1, 98-113.

---, (2007). "De Atenas a Chalco (Sin pasar por la Tcheka*)". En Fundación Andreu Nin., s/Vol., s/n de pág.

MORALES, Heberto. (2010). Jovel, Serenata a la gente menuda. Tuxtla Gutierrez, México: Consejo Estatal para la Cultura y las Artes.

ONFRAY, Michel. (2012). L'ordre libertaire. La vie filosophique d'Albert Camus. Paris: Flamarion. 